\title{
Is Altruism Important for Understanding the Long-Run Effects of Social Security?*
}

\author{
Luisa Fuster \\ Departament d'Economia i Empresa, \\ Universitat Pompeu Fabra, \\ Ramon Trias Fargas 25-27, \\ 08005 Barcelona, Spain.
}

This version: September, 1997.

\footnotetext{
*I thank the helpful comments of Ayse Imrohoroglu, Selo Imrohoroglu, Tim Kehoe, John Laitner, M. Antonia Oliver, and Ed Prescott. I especially owe thanks to Andrés Erosa for many useful suggestions. I also thank the Department of Economics of the University of Minnesota and the Department of Economics of the University of Western Ontario for their kind hospitality while I was working on this paper. Financial support of the Spanish Ministry of Education (grant PB941095) and Fulbright (grant FU94-21471056) is gratefully acknowledged.
} 


\begin{abstract}
.
This paper quantifies the effects of social security on capital accumulation and wealth distribution in a life cycle framework with altruistic individuals. The main findings of this paper are that the current U.S. social security system has a significant impact on capital accumulation and wealth distribution. I find that social security crowds out $8 \%$ of the capital stock of an economy without social security. This effect is driven by the distortions of labor supply due to the taxation of labor income rather than by the intergenerational redistribution of income imposed by the social security system. In contrast to previous analysis of social security, I found that social security does not affect the savings rate of the economy. Another interesting finding is that even though the current U.S. social security system is progressive in its benefits, it may lead to a more disperse distribution of wealth.
\end{abstract}




\section{Introduction}

The effects of the current U.S. social security system on capital formation have been the focus of great attention among economists. Using the life cycle framework, Auerbach and Kotlikoff (1987) find that the capital stock in the US economy could be $24 \%$ higher if the social security system was eliminated. On the other hand, the seminal work of Barro (1974) shows that in a dynastic framework an unfunded social security system has no effects on capital accumulation if each generation is linked to the next through bequests.

This paper quantifies the effects of social security on capital accumulation in a framework that embraces as special cases both the life cycle and the dynastic frameworks. All quantitative analyses of social security have used the overlapping generations model. ${ }^{1}$ This paper incorporates altruism into this framework in order to assess to what extent the findings in the literature are affected by the assumption of non-altruistic preferences. The answer will not be trivial as Barro (1974) suggests, since at the steady state of this model not every household will be linked by bequests. This is consistent with the finding that bequests in the US economy are concentrated in the upper wealth groups. ${ }^{2}$

Social security plays an insurance role that has not been analyzed so far. This paper emphasizes that altruistic individuals may benefit from a progressive social security system because it provides insurance against the possibility that a low income shock affects descendants. The analysis of this insurance role is of interest since the U.S. social security system is progressive in its benefits. ${ }^{3}$ This study looks at how this intragenerational redistribution of income affects the distribution of wealth in the economy.

\footnotetext{
${ }^{1}$ See, for example, Auerbach and Kotlikoff (1987), Hubbard and Judd (1987), and Imrohoroglu et al. (1995).

${ }^{2}$ See, for example, Hurd and Shoven (1985), Hurd (1987), and Juster and Laitner (1996).

${ }^{3}$ Pension benefits increase less than proportionally in relation to individuals' earnings.
} 
The results I have obtained show that the current U.S. social security system has a significant impact on capital accumulation. Social security crowds out $8 \%$ of the capital stock of an economy without social security. I have also found that the effect of social security on capital accumulation is driven by the distortions in labor supply decisions due to the social security taxes. This effect, though important, is significantly smaller than the one obtained in a life-cycle framework. ${ }^{4}$ In the life cycle framework, the intergenerational redistribution of income imposed by the social security system reduces the savings rate of the economy significantly. In a model with altruism, social security has no important effects on the saving rate of the economy. Social security does not affect the capital labor ratio because the capital stock changes proportionally to the total amount of labor supplied. In fact, if labor was supplied inelastically, social security would only crowd out $2 \%$ of the capital stock.

Surprisingly, social security leads to a more disperse distribution of wealth, even though the system is progressive in its benefits. Actually, I have found that the Gini coefficient of the distribution of assets increases from 0.46 to 0.58 with social security. This effect is caused by the intergenerational redistribution imposed by social security. Since individuals are altruistic, they would like to increase their bequests to compensate their children for the social security taxes. In addition, social security substitutes for life cycle savings. Consequently, the bequest motive becomes relatively more important than the life cycle motive in savings decisions. Since bequests are concentrated among the upper wealth groups, the distribution of assets becomes more concentrated. In fact, the share of assets of the richest $20 \%$ of households increases from $47 \%$ to $53 \%$, while the share of assets of the poorest $40 \%$ of households decreases from $8 \%$ to $1.3 \%$.

The model in this paper has four key features. First, it is an overlapping generations model. This way, the intergenerational transfers implemented by a social

\footnotetext{
${ }^{4}$ I also compute the steady state of a standard overlapping generations framework calibrated to the U.S. economy. In this case, the crowding out effect of the current social security system is $30 \%$ of the capital stock of an economy without social security.
} 
security system can be modeled. Second, individuals are altruistic. Altruism is modeled as two-sided, that is, individuals care about their predecessors and descendants. For the specification of preferences, I have followed Laitner (1992) in order to prevent parents and children from behaving strategically, as they may do in multiperiod overlapping generations models with altruism. Third, there is an idiosyncratic shock that affects the lifetime labor productivity of individuals. This shock evolves according to a stochastic process across generations of individuals within a dynasty. Fourth, negative bequests are not allowed. These four key features entail that in steady state equilibrium some households receive positive bequests while other households do not (see Laitner (1992)).

Many economists have quantified the long-run effects of social security on capital accumulation using the life cycle framework. ${ }^{5}$ In this framework a social security system transfers income from individuals with high marginal propensity to save (young) to individuals with low marginal propensity to save (old). Therefore, it is not surprising that in this framework social security has a significant negative effect on saving rates and capital accumulation. Barro (1974) has shown that these findings may be very sensitive to the consideration of altruistic preferences. Other economists have also explored the effects of social security in the presence of altruism. ${ }^{6}$ The contribution of this paper is to perform the first quantitative exercise.

Economists have also been concerned with the effects of social security on the distribution of wealth. Abel (1985) shows that in a life cycle framework with accidental bequests social security decreases the concentration of wealth. This paper adds to the literature by showing that even a progressive social security system can lead to a higher dispersion in the distribution of wealth when altruism is incorporated into the analysis.

Section 2 presents the model economy. Section 3 describes the calibration of the benchmark economy and reports the results of the numerical experiments. An

\footnotetext{
${ }^{5}$ Among the most relevant contributions are Hubbard and Judd (1987), Auerbach and Kotlikoff (1987), and Imrohoroglu et al. (1995).

${ }^{6}$ See Laitner (1988) and Altig and Davis (1993).
} 
Appendix contains the definition of steady state and a description of the algorithm to compute the steady state equilibrium.

\section{The Model}

The economy is populated by $2 T$ overlapping generations of individuals. An individual's life overlaps during the first $T$ periods with the life of his father and during the last $T$ periods with the life of his son (see Figure 1 ). Since there is no population growth, all cohorts have the same size, which is normalized to one.

\section{Altruistic Preferences}

Individuals derive utility from their lifetime consumption and leisure and from the felicity of their predecessors and descendants. As it was mentioned above, the formalization of preferences follows Laitner (1992). This author formulates a two-sided altruism model in which strategical behavior of father and son does not arise because their decisions maximize the same objective function. Because of this commonality of interests during the $T$ periods when their lives overlap, father and son constitute a single decision unit by pooling their resources and solving jointly a maximization problem. I call this decision unit a household. ${ }^{7}$

By a "dynasty" I mean a sequence of households that belong to the same family line. A household lasts $T$ periods. It begins with an adult male, the "father", of generation $i+j T$ and age $T+1$, and with a second adult male, the "son", of generation $i+j T+T$ and age 1. During the household's life span, the father's consumption and leisure are $\left\{c_{f}(t, i+j T), l_{f}(t, i+j T)\right\}_{t=1}^{T}$, and the son's consumption and leisure are $\left\{c_{s}(t, i+(j+1) T), l_{s}(t, i+(j+1) T)\right\}_{t=1}^{T}$. After $T$ periods, the father dies and the son becomes the father in the next-generation household of the dynasty. The expected utility of the dynasty as the household with a father of generation $(i+j T)$

\footnotetext{
${ }^{7}$ I omit women because I am assuming assortative mating as analyzed in Laitner (1991).
} 
begins, is

$E \sum_{j=0}^{\infty} \beta^{j T} \sum_{t=1}^{T} \beta^{t-1}\left\{u\left(c_{f}(t, i+j T), l_{f}(t, i+j T)\right)+u\left(c_{s}(t, i+T+j T), l_{s}(t, i+(j+1) T)\right)\right\}$,

The utility function is assumed to be

$$
u(c, l)=\frac{1}{1-\sigma}\left(c^{1-\gamma} l^{\gamma}\right)^{1-\sigma},
$$

where $\sigma$ is the inverse of the elasticity of intertemporal substitution and $\gamma$ represents the intensity of preferences for leisure relative to consumption. ${ }^{8}$

The utility of individuals is defined in expected terms because the labor ability of future members of the dynasty is unknown. Labor ability, $z \in Z=\{H, L\}$, becomes known when an individual is born and determines his lifetime profile of efficiency units of labor

$$
\epsilon_{z}(s)=\left\{\begin{array}{l}
\epsilon_{H}(s) ; \text { if } z=H \\
\epsilon_{L}(s) ; \text { if } z=L
\end{array}\right.
$$

where $s$ denotes an individual's age, $s=1,2, \ldots, 2 T$. If $z=H$, an individual has a high labor productivity and if $z=L$, an individual has a low labor productivity. At age $R$ and thereafter, the endowment of efficiency units of labor is zero, which implies that individuals retire from the labor market at age $R .^{9}$

Abilities are correlated intergenerationally. They follow a two-state first-order Markov chain with a stationary distribution $\mu$. The transition probability matrix for the labor ability state is given by the matrix

$$
\Pi\left(z^{\prime}, z\right)=\left[\pi_{i j}\right] ; \quad i, j \in\{H, L\}
$$

where $\pi_{i j}=\operatorname{Pr}\left\{z^{\prime}=j \mid z=i\right\}, z^{\prime}$ is the labor ability of the new born in the dynasty, and $z$ is the labor ability of his father. It is important to note that there are no insurance markets in the economy.

\footnotetext{
${ }^{8}$ A unitary elasticity of substitution between consumption and leisure is a reasonable assumption since hours of work per household have maintained constant for the last four decades, in spite of a large rise in the real wage rate. See, for example, Kydland and Prescott (1996).

${ }^{9}$ Each period, an individual is endowed with one unit of time. The endowment of effective labor per unit of time is the number of efficiency units of labor.
} 


\section{Technology}

There are firms in this economy that use capital, $K$, and effective labor, $N$, to produce a single good according to the following production function:

$$
Y=K^{\alpha} N^{1-\alpha}
$$

where $\alpha \in(0,1)$ is the capital share of output. Capital depreciates at a constant rate $\delta \in(0,1)$. Firms maximize profits hiring capital and labor services so that marginal products equal inputs' prices, that is,

$$
\begin{aligned}
& r=\alpha K^{a-1} N^{1-\alpha}-\delta \\
& \omega=(1-\alpha) K^{\alpha} N^{-\alpha} .
\end{aligned}
$$

\section{Social Security}

The social security system provides pension benefits to retired individuals and taxes labor income. The tax rate is set so that the budget of the social security system is balanced in each time period. I assume that the benefits that individuals receive are related to their average lifetime earnings according to a linear function. As it will become evident later, this linearity in the benefit formula will greatly simplify the computational problem. In order to capture the progressivity of the social security system, I will choose a different benefit formula for high and low labor ability individuals (see the calibration section of the paper).

\section{The Maximization Problem of a Household}

Writing the maximization problem of a household in the terms of dynamic programing language simplifies its computation. In order to express the household problem in these terms, I will divide it in two stages. In the first stage, newly created households maximize the discounted sum of utilities over the $T$ periods that the households last. In this problem households take both the initial wealth and the final wealth that they will leave to the next household as given. In the second stage, households decide the optimal amount of wealth that they will transfer to the next household in the dynasty. 
Note that wealth is composed of asset holdings and the present value of social security claims that individuals have accumulated. Pension wealth and asset holdings differ in their liquidity since the pension wealth cannot be consumed until an individual retires from the labor market. During retirement individuals receive a pension which depends on their average lifetime earnings. Pension is related to an individual's average lifetime earnings according to the linear function $b(\cdot)$, being an individual's average lifetime earnings the index

$$
m=\omega \sum_{t=1}^{T} \frac{n_{s}(t) \epsilon_{z}(t)+n_{f}(t) \epsilon_{z}(t+T)}{R-1}
$$

where $n_{s}(t)$ and $n_{f}(t)$ are the fractions of time allocated to work by an individual while he was a son and while he was father, respectively. The linearity of the benefit formula leads to

$$
b(m)=\sum_{t=1}^{T} \frac{b\left(\omega n_{s}(t) \epsilon_{z}(t)\right)}{R-1}+\sum_{t=1}^{T} \frac{b\left(\omega n_{f}(t) \epsilon_{z}(t+T)\right)}{R-1} .
$$

The first part of the above expression are the social security claims that an individual accumulated during the first part of his life. The present value of these social security claims is the initial pension wealth of a newly created household which is denoted by $p$, that is

$$
p=\sum_{t=1}^{T} \frac{b\left(\omega n_{s}(t) \epsilon_{z}(t)\right)}{R-1} \sum_{t=R-T}^{T} \frac{1}{(1+r)^{t-1}} .
$$

As a consequence, the present value of an individual's pension at age $T+1$ is

$$
p+\sum_{t=1}^{T} \frac{b\left(\omega n_{f}(t) \epsilon_{z}(t+T)\right)}{R-1} \sum_{t=R-T}^{T} \frac{1}{(1+r)^{t-1}} .
$$

The first stage of the maximization problem is restricted by the following constraint:

$$
\begin{aligned}
\sum_{t=1}^{T} \frac{c_{f}(t)+c_{s}(t)}{(1+r)^{t-1}}+ & \frac{a^{\prime}}{(1+r)^{T}}=a+p+\omega(1-\tau) \sum_{t=1}^{T} \frac{n_{s}(t) \epsilon_{z}(t)+n_{f}(t) \epsilon_{z^{\prime}}(t+T)}{(1+r)^{t-1}}+ \\
& +\sum_{t=1}^{T} \frac{b\left(\omega n_{f}(t) \epsilon_{z}(t+T)\right)}{R-1} \sum_{t=R-t}^{T} \frac{1}{(1+r)^{t-1}},
\end{aligned}
$$


where $a^{\prime}$ denotes asset holdings to be transferred to the next household in $T$ periods, $a$ stands for asset holdings in the current period, $\tau$ is the social security tax, and $t$ denotes the age of the household. The above constraint entails that the present value of consumption by both father and son, plus the present value of transfers of asset holdings to the next household in the dynasty, are restricted by the sum of asset holdings, present value of labor income, and present value of social security benefits.

In the first stage of the maximization problem, newly formed households take as given the initial amount of assets and pension wealth and the final a mount of assets and final pension wealth to be transferred to the next household, and the abilities of both father and son. This optimization problem defines an indirect utility function $F(\cdot)$,

$$
\begin{gathered}
F\left(a, p, a^{\prime}, p^{\prime}, z, z^{\prime}\right) \equiv \\
\max _{\left\{c_{f}(t), l_{f}(t), n_{f}(t), c_{s}(t), l_{s}(t), n_{s}(t)\right\}_{t=1}^{T}} \sum_{t=1}^{\infty} \beta^{t-1}\left[u\left(c_{f}(t), l_{f}(t)\right)+u\left(c_{s}(t), l_{s}(t)\right)\right]
\end{gathered}
$$

subject to:

Eq.(2.3),

$$
\begin{array}{r}
n_{s}(t)+l_{s}(t)=1 \text { and } n_{f}(t)+l_{f}(t)=1, \forall t, \text { and } \\
p^{\prime}=\sum_{t=1}^{T} \frac{b\left(\omega n_{s}(t) \epsilon_{z}(t)\right)}{R-1} \sum_{t=1}^{T} \frac{1}{(1+r)^{t-1}},
\end{array}
$$

where $p^{\prime}$ represents the pension wealth that is left to the next household.

In the second stage, households decide the asset holdings and pension wealth that they will leave to the next household in the dynasty. This decision problem is represented with the functional equation that follows:

$v\left(a, p, z, z^{\prime}\right)=\max _{\left\{a^{\prime}, p^{\prime}\right\}}\left\{F\left(a, p, a^{\prime}, p^{\prime}, z, z^{\prime}\right)+\beta^{T}\left[\pi_{z^{\prime} H} v\left(a^{\prime}, p^{\prime}, z^{\prime}, H\right)+\pi_{z^{\prime} L} v\left(a^{\prime}, p^{\prime}, z^{\prime}, L\right)\right]\right\}$

subject to:

$$
a^{\prime}+p^{\prime} \geq 0
$$


The borrowing constraint in the above maximization problem implies that negative transfers of wealth between households are not allowed. ${ }^{10}$ Note that I am allowing households to borrow up to the present value of social security claims. This simplifies to a great extent the computation of a solution to the functional equation, since the value function actually depends on the sum of asset holdings and pension wealth rather than on each of them individually. Since households can borrow against their pension wealth, what matters is their total wealth and not the composition of their wealth. Thus, problem (2.4) can be written with only one endogenous state variable representing $\tilde{a} \equiv a+p$. Therefore, the state of a newly formed household is the three-tuple $\left(\tilde{a}, z, z^{\prime}\right)$ and the solution is characterized by an optimal policy function of final wealth $\widetilde{a}^{\prime}=h\left(\widetilde{a}, z, z^{\prime}\right)$.

\section{Distribution of Households}

The space of possible states of a household is discretized by requiring the initial assets of a household to fall in a finite grid $G=\left\{G_{1}, G_{2}, \ldots, G_{50}\right\}$. Therefore, the space of possible states is $G \times Z \times Z$. There is an invariant distribution of households, $X$, which is defined on the $\sigma$-algebra of subsets of $G \times Z \times Z$. The law of motion of this distribution is consistent with the households' optimization behavior and with the stochastic process of the ability shock.

\section{Steady State}

A Steady State for a given social security arrangement $(b, \tau)$ consists of policy functions $\left(c_{f}, c_{s}, l_{f}, l_{s}, n_{f}, n_{s}, h\right)$, aggregate capital, labor, and consumption $(K, N, C)$, prices $(\omega, r)$, and the distribution of households $X$, such that policies $\left(c_{f}, c_{s}, l_{f}, l_{s}, n_{f}, n_{s}, h\right)$ are optimal, prices are competitively determined, markets clear, the distribution $X$ remains invariant and, social security's budget is balanced in each period. The formal definition of steady state is provided in the Appendix.

\footnotetext{
${ }^{10}$ In models with altruistic preferences it is usual to impose a non-negativity constraint on bequests (for instance, see Barro (1974)).
} 


\section{Long-Run Effects of Social Security}

In this section, I quantify the effects of social security on capital accumulation and wealth distribution. In order to interpret the numerical results, one should know previously to what extent social security affects the economy. ${ }^{11}$ Social security substitutes for life-cycle savings because it redistributes income from the working periods to the retirement. It also affects the bequest decision, thus also having important consequences for capital accumulation and the distribution of wealth.

In this framework social security plays an insurance role that has not been emphasized so far. Because altruism is two-sided and there is an uninsurable shock on the earnings of children, individuals face the risk of having a son that cannot afford to support them during retirement. In such an economy a progressive social security system plays the role of insurance because it reduces the variability of a household's earnings during retirement. Consequently, social security substitutes for precautionary savings. ${ }^{12}$ The progressivity of social security may also lead to significant labor supply distortions. This may affect savings due to a negative income effect.

Social security affects intervivos transfers and bequests. In order to understand these effects, let's consider a simple case of this model in which individuals live for two time periods (a household lasts for one period, i.e. $T=1$ ) and social security benefits are independent of past earnings and are financed by lump-sum taxes. In this economy, social security redistributes income within a household from the son to the father. This mandatory transfer can be offset by an intervivos transfer from

\footnotetext{
${ }^{11}$ In this environment Ricardian neutrality fails because in each period some households end up being constrained. This is because the steady state interest rate is lower than the discount rate. The proof of this property of the interest rate is available upon request from the author. This property has been shown in income fluctuation models (Huggett (1997)) and in models with altruistic preferences and lifetime uncertainty (Fuster (1994)). In income fluctuation models, Bewley (undated) and Laitner (1992) have proved the existence of a steady state where the interest rate satisfies the aforementioned condition.

${ }^{12}$ Barsky et al. (1986) showed that when individuals are uncertain about the income of their heirs, a nonlump-sum tax on their heirs' income reduces its variance and then reduces the desired bequest.
} 
the father to the son. As a result, consumption, savings, and bequests remain the same and only intervivos transfers are affected by social security. Consider now the case where individuals live for four periods (a household lasts two periods, i.e. $T=2$ ) and are retired the last period of their life. Social security redistributes income across households of different ages, from young to old households (that is, from age 1 to age 2 households). Therefore, social security affects the profile of earnings of a dynasty reducing the earnings of young households and increasing the earnings of old households. Since the utility function is concave, dynasties prefer a smooth consumption profile and would like to offset the redistribution forced by social security. This will be possible by increasing the bequest (or the wealth) left to the next young household in the dynasty.

Social security affects the distribution of wealth in a non-trivial way. The progressivity of social security induces an equalizing effect. On the other hand, since households leave a higher bequest with social security than without it, the range of the distribution of bequests increases. This may lead to a more spread distribution of bequests and, therefore, to an increase in wealth inequality.

As regards the welfare effects of social security, they are theoretically ambiguous in this framework. Social security crowds-out capital which has a positive or negative effect on welfare depending on whether the economy is dynamically inefficient or not. ${ }^{13}$ In addition, social security provides insurance against the risk of having a bad income shock during retirement. On the other hand, the pension benefits are financed by taxes that distort the labor supply decision.

In the next subsections I quantify the long-run effects of the U.S. social security system. To this end, I calibrate the model economy so that its steady state equilibrium is consistent with some observations upon the U.S. economy. Then, I compute the steady state of an economy without social security and compare capital accumulation, wealth distribution, and welfare across both steady states. In the last subsections, I study the role played by the assumptions of elastic labor supply and

\footnotetext{
${ }^{13}$ Imrohoroglu et al. (1995) found that social security eliminates the dynamic inefficiency of equilibria in a model calibrated to U.S. economy.
} 
altruistic preferences in generating the results.

\subsection{Calibration}

The artificial economy is calibrated to match selected observations of the U.S. postwar economy. Following Auerbach and Kotlikoff (1987), I assume that individuals start their economic life at age 20 , retire at age 65 , and die at age 80 . For computational reasons a model period is five years. This implies $R=10$ and $T=6$.

\section{Technology and Utility}

The capital share of production, $\alpha$, the depreciation rate, $\delta$, and the discount factor, $\beta$, are chosen to match a capital share of GNP of 0.36 (Prescott (1986)), a capital-output ratio of 3 , and a risk-free interest rate of 0.045 . Therefore, I obtain $\alpha=0.36, \delta=0.08$, and, $\beta=0.955$, the last two being expressed in annual terms. ${ }^{14}$

The parameter $\gamma$, which represents the intensity of preferences for leisure relative to consumption, is chosen so that individuals allocate $40 \%$ of their time to work (Auerbach and Kotlikoff (1987)). This implies $\gamma=0.6$.

There is an ample range of estimated values for the coefficient of relative risk aversion. Auerbach and Kotlikoff (1987) cite empirical studies that provide estimations of $\sigma$ in the range of 1 to 10 . I have followed the social security analysis by Auerbach and Kotlikoff (1987) which choose $\sigma=4$.

\section{Labor Productivity}

The profiles of efficiency units of labor for high and low abilities, $\epsilon_{z}(s)$, are calibrated to the profiles of efficiency units of labor of college and non-college graduate males respectively. These indexes are taken from Cubeddu (1996), who constructed indexes of labor efficiency units for four categories of individuals regarding gender and education. I consider the two male categories reported by Cubeddu (1996). I

\footnotetext{
${ }^{14}$ Since in the steady state $1+r<1 / \beta$, I have to search on $\beta$ until the equilibrium interest rate is close to 0.045 .
} 
normalize the indexes to average one. Table 2 presents these indexes. ${ }^{15}$

I chose values for the transition probabilities to match the two following observations: First, the proportion of full-time male workers that were college graduate in 1991 was 28\% (see Bureau of the Census (1991), pg. 145). Second, the correlation between a permanent component of income of parents and children is 0.4 according to estimations by Zimmerman (1992) and Solon (1992). These observations imply for this model that $\pi_{H H}=0.57$ and $\pi_{L L}=0.83$.

Table 1: List of Parameters

\begin{tabular}{|c|c|c|c|}
\hline \multicolumn{4}{|c|}{ Population } \\
\hline $2 T$ & $=$ & 12 & Lifetime of individuals (60 years) \\
\hline \multirow[t]{2}{*}{$R$} & $=$ & 10 & Retirement age ( 45 years) \\
\hline & & \multicolumn{2}{|l|}{ Utility } \\
\hline$\gamma$ & $=$ & 0.6 & Intensity of preferences for leisure. \\
\hline$\sigma$ & $=$ & 4 & Coefficient of relative risk aversion. \\
\hline \multirow[t]{2}{*}{$\beta$} & $=$ & 0.955 & Annual discount factor of utility. \\
\hline & & \multicolumn{2}{|l|}{ Production } \\
\hline$\alpha$ & $=$ & 0.36 & Capital share of GNP. \\
\hline$\delta$ & $=$ & 0.08 & Annual depreciation rate. \\
\hline$\epsilon_{z}(s)$ & & (see Table 2.) & Efficiency units of labor \\
\hline$\mu(H)$ & $=$ & 0.28 & Measure of individuals with high ability. \\
\hline$\pi_{z z^{\prime}}$ & & & Transition probability matrix of abilities. \\
\hline$\pi_{L L}=0.83$ & and & $\pi_{H H}=0.57$ & \\
\hline
\end{tabular}

\footnotetext{
${ }^{15}$ Cubeddu (1996) uses the same methodology as Hansen (1991). He calculates the indexes of efficiency units of labor using data on wages.
} 
Table 2: Endowment of efficiency units of labor.

\begin{tabular}{||r|r|r||}
\hline \hline Age & College & Non-college \\
\hline \hline $20-24$ & 0.73 & 0.45 \\
\hline $25-29$ & 1.00 & 0.70 \\
\hline $30-34$ & 1.21 & 0.84 \\
\hline $35-39$ & 1.35 & 0.90 \\
\hline $40-44$ & 1.46 & 0.94 \\
\hline $45-49$ & 1.54 & 0.97 \\
\hline $50-54$ & 1.61 & 0.98 \\
\hline $55-59$ & 1.66 & 0.99 \\
\hline $60-64$ & 1.68 & 0.95 \\
\hline age $>65$ & 0.00 & 0.00 \\
\hline \hline
\end{tabular}

\section{Social Security}

Social security pensions depend on the average earnings of individuals over their 35 years of highest earnings. This relation is non-linear since the marginal replacement rate of social security decreases with an individual's earnings (see Figure 2). ${ }^{16}$ For each dollar of earnings bellow $20 \%$ of the average earnings in the economy, social security benefits are 90 cents. For each dollar of earnings between $20 \%$ and $125 \%$ of the average earnings in the economy, the social security benefit is 32 cents. Each additional dollar of earnings up to $246 \%$ of the average earnings in the economy receives 15 cents of benefit. Above that level of earnings the marginal replacement rate is zero.

In order to capture the progressivity of social security, I use different benefit formulas for individuals of low labor ability and of high labor ability, which are,

\footnotetext{
${ }^{16}$ The marginal replacement rate is the benefit that the last dollar of earnings entitles. See Feldstein and Samwick (1992) and Cubeddu (1996), who provide a detailed description of the U.S. social security benefit formula.
} 
respectively

$$
\begin{gathered}
b_{L}(m)=0.32(m-0.2 \bar{m})+0.9 \cdot 0.2 \bar{m} \\
b_{H}(m)=0.15(m-1.25 \bar{m})+0.32(1.25 \bar{m}-0.2 \bar{m})+0.9 \cdot 0.2 \bar{m}
\end{gathered}
$$

where $m$ represents the average lifetime earnings of an individual, and $\bar{m}$ denotes the average earnings in the economy.

Figure 2 represents the benefit functions used in this paper and the benefit function of the U.S. economy. Note that the functions $b_{L}(\cdot)$ and $b_{H}(\cdot)$ satisfy the following properties: (1) $b_{i}(\cdot) \geq b_{U . S .}(\cdot)$ for $i=L, H$; and $(2) b_{L}(m)=b_{U . S .}(m)$ for $m \in[0.20 \bar{m}, 1.25 \bar{m}]$ and $b_{H}(m)=b_{\text {U.S. }}(m)$ for $m \in[1.25 \bar{m}, 2.46 \bar{m}]$. These properties guarantee that when low labor ability individuals have earnings belonging to the interval $[0.20 \bar{m}, 1.25 \bar{m}]$, the solution of the household maximization problem coincides with the one obtained if we had used the U.S. benefit formula. ${ }^{17}$ A similar conclusion applies for high labor ability individuals when their average lifetime earnings belong to the interval $[1.25 \bar{m}, 2.46 \bar{m}]$. In the numerical experiments the first condition is satisfied by all individuals of low labor ability, and the second condition is satisfied by all individuals of high labor ability.

\section{Welfare}

For welfare comparisons I choose the utilitarian criteria, that is

$$
W(\tau) \equiv \sum_{\left(\widetilde{a}, z, z^{\prime}\right) \in G \times Z \times Z} v\left(\tilde{a}, z, z^{\prime}\right) \cdot X\left(\tilde{a}, z, z^{\prime}\right) .
$$

where $W(\tau)$ denotes the welfare associated with the social security tax $\tau$. The measure of welfare benefit of alternative social security arrangements is the percentage of variation of consumption required to make a household of age 1 indifferent between living in an economy without social security, or in the benchmark economy. ${ }^{18}$

\footnotetext{
${ }^{17}$ If $\hat{x}=\arg \max \{f(x)$ s. to $x \in A\}$, and $\widehat{x} \in B \subseteq A$, then it is true that $\widehat{x}=$ $\arg \max \{f(x)$ s. to $x \in B\}$.

${ }^{18}$ Since the welfare function is homogeneous of degree $(1-\gamma)(1-\sigma)$ with respect to consumption, the consumption variation $(c)$ necessary to make a household indifferent between living in an
} 


\subsection{Findings.}

Social security has significant effects on capital accumulation and wealth distribution. In fact, the results of this experiment show that the actual U.S. social security crowds-out $8 \%$ of the capital stock of an economy without social security. However, the capital-labor ratio and, therefore, the savings rate of the economy are not significantly affected by social security. ${ }^{19}$ Another interesting finding is that the distribution of assets becomes more disperse with social security, even though the system is progressive in its benefits.

Social Security and Capital Accumulation. Social security crowds-out $8 \%$ of the capital stock of an economy without social security. This crowding-out effect, though significant, is smaller than the one found in life cycle analyses. ${ }^{20}$ In a standard life cycle model, social security redistributes income from young individuals, who have high marginal propensity to save, to old individuals, who have low marginal propensity to save. This leads to a significant decrease in the savings rate of the economy, and, hence, to a large negative effect on capital accumulation. Yet, in a model with altruism, old households save for bequest motives and thus, they do not necessarily have a lower marginal propensity to save than younger households. In fact, old households would like to compensate the tax burden of future generations by increasing their bequests. This explains why the savings rate of the economy is not significantly affected by social security. As a consequence, the impact on the capital-labor ratio of the economy is small (see Table 3 ).

As will be explained later, the effects of social security on labor supply are also important to understand the crowding out effect on capital accumulation. Labor economy without social security or in the benchmark economy, satisfies

$$
(1+c)^{(1-\gamma)(1-\sigma)} \cdot W(0 .)=W(\tau)
$$

\footnotetext{
${ }^{19}$ Note that in the steady state the savings rate is equal to $\frac{\delta K}{Y}$ which is equal to $\delta(K / L)^{1-\alpha}$.

${ }^{20}$ Auerbach and Kotlikoff (1987) and Imrohoroglu et al. (1995) found that the U.S. social security crowds-out more than $20 \%$ of the capital stock of an economy without social security.
} 
supply decreases $6.3 \%$ with social security. The decrease in the number of hours allocated to work is more important for younger individuals $(8 \%)$ than for older individuals $(4 \%)$. This is because the tax net of marginal benefit decreases with age.

Table 3:

\begin{tabular}{|c|c|c|c|c|}
\hline \multicolumn{5}{|c|}{ Benchmark Economy } \\
\hline & $K / Y$ & $r$ & $\tau$ & hours \\
\hline & 3.1 & 0.043 & 0.15 & $39 \%$ \\
\hline \multicolumn{5}{|c|}{ Aggregate Effects of Social Security } \\
\hline$\tau$ & $K$ & $N$ & $C$ & $\delta K / Y$ \\
\hline 0.0 & 100 & 100 & 100 & $21.6 \%$ \\
\hline 0.15 & 92 & 93.8 & 93.5 & $21.3 \%$ \\
\hline
\end{tabular}

Distributional Effects of Social Security. Even though social security implies less dispersion of income, it induces more dispersion of assets. ${ }^{21}$ Table 4 reports data on the distribution of asset holdings. It is striking that the share of assets of the poorest $40 \%$ of households decreases from $8 \%$ to $1.3 \%$ with social security. To understand this observation, note that poor households save mainly for smoothing consumption along the life cycle. Since social security substitutes for life cycle savings, the share of assets of the poorest households drops dramatically. On the other hand, the share of assets of the richest $20 \%$ of households increases from $47 \%$ to $53 \%$. This is due to the fact that social security induces an increase in bequests which is important among wealthy households. This increase in bequests is reflected in the assets owned by newly created households which increase from $30 \%$ to $40 \%$ of output. In addition, the number of households that face a binding interhousehold borrowing constraint decreases from $45 \%$ to $29 \%$ of households with social security.

\footnotetext{
${ }^{21}$ The Gini coefficient of the distribution of income decreases with social security from 0.16 to 0.11, while the Gini coefficient of the distribution of assets increases from 0.46 to 0.58 .
} 
Table 4: Distribution of Assets

\begin{tabular}{|c||cccccc|}
\hline \multicolumn{8}{|c|}{ Share of total sample in each asset holdings group } \\
\multicolumn{1}{|c|}{ Gini } & Bottom $40 \%$ & Top $20 \%$ & $10-5 \%$ & $5-1 \%$ & $1 \%$ \\
\hline 0.0 & 0.46 & 7.9 & 47.3 & 12 & 12.1 & 3.9 \\
0.15 & 0.58 & 1.3 & 53.3 & 14 & 13.5 & 4.3 \\
\hline
\end{tabular}

Welfare Social security has significant negative welfare effects. Indeed, the permanent reduction in consumption necessary to make a household indifferent between living in an economy without social security and in an economy with the actual system amounts to $2 \%$. Table 5 reports the average welfare cost for four types of households. These types are defined by the labor abilities of the father and son. Welfare is measured by the sum of utilities across households of the given type. Note that welfare decreases for all household types. The welfare cost is the highest for the household with high labor ability individuals. The increase in the dispersion of wealth explains why even households with individuals of low labor ability are worse off with social security.

Table 5: Welfare.

\begin{tabular}{|ccccc|}
\hline \multicolumn{5}{|c|}{ \%-Consumption compensation } \\
\hline overall & $H H$ & $H L$ & $L H$ & $L L$ \\
-2 & -5 & -3.4 & -3.7 & -1.3 \\
\hline
\end{tabular}

\subsection{The Importance of Labor Distortions}

In this subsection I analyze the role played by labor distortions in generating the results of the previous section. I show that labor distortions are a key factor in generating a significant crowding out effect of social security; however, they are not important in explaining the distributional effects of social security. 
I quantify the effects of social security in a version of the model economy where labor is supplied inelastically. In this exercise I calibrate the model economy to the capital share of income, interest rate, and capital output ratio used in the previous section. I pick $\sigma$ so that the exponent of consumption in the utility function is the same as the one used when leisure was valued. ${ }^{22}$ I use indexes of efficiency units of labor that I calculated using data on earnings rather than wages. This way, the indexes capture not only differences in labor productivities, but also differences in working hours. ${ }^{23}$.

Table 6 shows that when labor supply is inelastic, the crowding out effect of social security is small. It is only $2 \%$ of the capital stock of an economy without social security. As in the model with elastic labor supply, the savings rate of the economy is not affected by the social security system. It is surprising that social security has important welfare costs since its consequences for aggregate output and consumption are not significant (see tables 6 and 7 ). Note that welfare decreases for all household types with social security. However, households where both father and son are of low labor ability enjoy a higher aggregate consumption with social security. Their welfare decreases because consumption is more dispersed with social security.

Table 6: Inelastic Labor Supply

\begin{tabular}{|c|c|c|c|c|}
\hline & $K / Y$ & $r$ & $\tau$ & \\
\hline & 3.1 & 0.043 & 0.15 & \\
\hline Agg & gate & fffects & of So & Security \\
\hline$\tau$ & $K$ & $Y$ & $C$ & $\delta K / Y$ \\
\hline 0.0 & 100 & 100 & 100 & $21.5 \%$ \\
\hline 0.15 & 98 & 99.3 & 99.6 & $21.3 \%$ \\
\hline
\end{tabular}

\footnotetext{
${ }^{22}$ I choose $\sigma$ such that $1-\sigma=\left(1-\sigma_{e}\right)(1-\gamma)$, where $\sigma_{e}=4$ and $\gamma=0.6$. This gives $\sigma=2.2$.

${ }^{23}$ The results that follow are not sensitive to the efficiency units profile used.
} 


\section{Table 7: Welfare.}

\begin{tabular}{|ccccc|}
\hline \multicolumn{6}{|c|}{ \%-Consumption compensation. } \\
\hline overall & $H H$ & $H L$ & $L H$ & $L L$ \\
-2.6 & -4.6 & -3 & -4 & -2 \\
\hline
\end{tabular}

Table 8 reports the average consumption of each household type. All figures are normalized by the value of average consumption of the household type $H H$ in the steady state without social security. The table shows that differences in average consumption across household types decrease with social security. This is a consequence of the progressivity of the pension benefit formula. However, the consumption variation coefficient increases with social security from 0.26 to 0.3 . The inequality in consumption increases as a result of the effect of social security on the distribution of wealth in the economy. As in the case of elastic labor supply, social security leads to an increase in wealth inequality. ${ }^{24}$

Table 8:

Consumption over the highest

\begin{tabular}{|c||cccc|}
\hline$\tau$ & $H H$ & $H L$ & $L H$ & $L L$ \\
0.0 & 1 & 0.81 & 0.81 & 0.63 \\
0.15 & 0.96 & 0.80 & 0.80 & 0.64 \\
\hline
\end{tabular}

\subsection{The Importance of Altruism for a Social Security Analysis.}

This subsection looks at the importance of altruism in analyzing the effects of social security, and shows that incorporating altruism changes dramatically the impact of social security on capital accumulation and distribution of wealth.

I quantify the effects of social security in a version of the model economy with non-altruistic individuals. This exercise calibrates the model economy to the same

\footnotetext{
${ }^{24}$ The Gini coefficient of the distribution of asset holdings increases from 0.5 to 0.68 with social security.
} 
observations than in the previous exercises. The parameter values are as shown in tables 1 and 2, except for the discount factor which is set to $1.01 .{ }^{25}$

Table 9 shows that the crowding out effect of social security is about 4 times larger in the life cycle model than in the dynastic economy. In a life cycle model, old individuals do not leave bequests. This involves that old individuals have a lower marginal propensity to save than young individuals. Therefore, the intergenerational redistribution of income by social security has a strong impact on the savings rate of the economy and, as a consequence, on capital accumulation. On the other hand, in a dynastic model the intergenerational redistribution of income has no impact on the savings rate of the economy. In this case, the crowding out effect on capital accumulation is driven by labor distortions. ${ }^{26}$

As regards the distributional effects of social security, it leads to a more egalitarian distribution of assets in a life cycle model. ${ }^{27}$ On the contrary, when individuals are altruistic social security induces a more unequal distribution of wealth.

Table 9: Aggregate Effects of Social Security

\begin{tabular}{|c||ccc||ccc|}
\hline & \multicolumn{1}{||||}{ Dynastic } & Economy & \multicolumn{3}{|c|}{ Life-Cycle } & Model \\
\hline$\tau$ & $K$ & $N$ & $\delta K / Y$ & $K$ & $N$ & $\delta K / Y$ \\
0.0 & 100 & 100 & 0.213 & 100 & 100 & 0.26 \\
0.15 & 92 & 93.8 & 0.216 & 69 & 94 & 0.21 \\
\hline
\end{tabular}

\footnotetext{
${ }^{25}$ This value of $\beta$ is chosed to match an interest rate of 0.045 . Since this is not a dynastic model, the discount factor of utility is not restricted to be lower than one. In fact, previous quantitative life cycle analysis have taken $\beta=1.011$ from an estimation by Hurd(1989). See, for example Imrohoroglu et al. (1995).

${ }^{26}$ In the life cycle analysis, I have made sure that the magnitude of the crowding out effect does not depend on whether labor supply is elastic or inelastic.

${ }^{27}$ The Gini coefficient of the distribution of asset holdings decreases with social security from 0.49 to 0.44 .
} 


\section{Conclusions}

This paper shows that altruism may be very important in understanding the effects of social security. In contrast to life cycle analyses, I have found that social security does not affect the savings rate in the economy. The social security system affects capital accumulation significantly because it distorts labor supply decisions.

Social security redistributes income intragenerationally and intergenerationally. The role of insurance played by the intragenerational redistribution of income has not proven significant. On the contrary, the intergenerational redistribution of income increases the dispersion of bequests which, in turn, makes the concentration of wealth rise.

\section{Appendix}

\subsection{Steady State}

This subsection contains the definition of steady state equilibrium. This definition requires us to clarify some notations. Father's and son's optimal policy functions of consumption are denoted by $c_{f}\left(t, \tilde{a}, \tilde{a}^{\prime}, z, z^{\prime}\right)$ and $c_{s}\left(t, \tilde{a}, \tilde{a}^{\prime}, z, z^{\prime}\right)$ respectively. The optimal policy functions of labor supply are $n_{f}\left(t, \tilde{a}, \tilde{a}^{\prime}, z, z^{\prime}\right)$ for the father and $n_{s}\left(t, \tilde{a}, \tilde{a}^{\prime}, z, z^{\prime}\right)$ for the son.

The optimal policy function of pension wealth is denoted by $p_{f}(t, S)$ for the father and by $p_{s}(t, S)$ for the son, where $S \equiv\left(\widetilde{a}, \tilde{a}^{\prime}, z, z^{\prime}\right)$. These functions are, respectively,

$$
p_{f}(t, S)=\sum_{i=1}^{t} \frac{b\left(\omega n_{f}(i, S) \epsilon_{z}(i+T)\right)}{R-1} \cdot \sum_{j=R}^{2 T} \frac{1}{(1+r)^{j-(t+T)}},
$$

and

$$
p_{s}(t, S)=\sum_{i=1}^{t} \frac{b\left(\omega n_{s}(i, S) \epsilon_{z^{\prime}}(i)\right)}{R-1} \cdot \sum_{j=R}^{2 T} \frac{1}{(1+r)^{j-t}},
$$

where $p_{s}(T, S)=p^{\prime} /(1+r)$. 
The optimal policy function of assets holdings is denoted by $g(t, S)$ and is obtained using the budget constraints of the household,

$$
\begin{aligned}
g(t, S)-(1+r) g(t-1, S)= & p_{f}(t, S)-(1+r) p_{f}(t-1, S)+p_{s}(t, S)- \\
& -(1+r) p_{s}(t-1, S)+\omega(1-\tau) \cdot\left(n_{f}(t, S) \epsilon_{z}(t+T)+\right. \\
& \left.+n_{s}(t, S) \epsilon_{z^{\prime}}(t)\right)-c_{f}(t, S)-c_{s}(t, S),
\end{aligned}
$$

where $p_{f}(0, S)=p_{s}(0, S)=0, \quad g(0, S)=\tilde{a} /(1+r) \quad$ and $\quad g(T, S)=\widetilde{a}^{\prime} /(1+r)$.

Definition: A Steady State for a given social security arrangement $(b(\cdot), \tau)$ is characterized by the prices of labor and capital services $(\omega, r)$, the indirect utility functions $F$ and $v$, policy functions $c_{f}, c_{s}, l_{f}, l_{s}, n_{f}, n_{s}, g$, and $h$ and an invariant distribution of households $X$ such that:

1. Given $(\omega, r)$ and $(b(\cdot), \tau)$, the functions $F$ and $v$ are the indirect utility functions of the household's maximization problems (2.4) and (2.5) respectively.

2. Given $(\omega, r)$ and $(B(\cdot), \tau)$, the policy rules $c_{f}, c_{s}, l_{f}, l_{s}, n_{f}, n_{s}$, and $g$ solve the household's maximization problem (2.4) and $h$ solves (2.5).

3. Prices of inputs satisfy,

$$
r=\alpha K^{\alpha-1} N^{1-\alpha}-\delta, \text { and } \omega=(1-\alpha) K^{\alpha} N^{-\alpha} \text {. }
$$

4. Markets clear, respectively,

Capital market:

$$
\begin{aligned}
& K=\sum_{t=1}^{T}\left[\sum_{A \times Z \times Z} X\left(\widetilde{a}, z, z^{\prime}\right) \cdot g\left(t, \tilde{a}, h\left(\widetilde{a}, z, z^{\prime}\right), z, z^{\prime}\right)-\sum_{A \times Z \times Z} X\left(\widetilde{a}, z, z^{\prime}\right) \cdot p_{s}\left(t, \tilde{a}, h\left(\widetilde{a}, z, z^{\prime}\right), z, z^{\prime}\right)-\right. \\
& \left.-\sum_{A \times Z \times Z} X\left(\tilde{a}, z, z^{\prime}\right) \cdot p_{f}\left(t, \tilde{a}, h\left(\tilde{a}, z, z^{\prime}\right), z, z^{\prime}\right)-\sum_{A \times Z \times Z} X\left(\tilde{a}, z, z^{\prime}\right)(1+r)^{t-1} p_{s}\left(T, \tilde{a}, h\left(\tilde{a}, z, z^{\prime}\right), z, z^{\prime}\right)\right] .
\end{aligned}
$$


Labor market:

$N=\sum_{A \times Z \times Z} X\left(\tilde{a}, z, z^{\prime}\right) \cdot \sum_{t=1}^{T}\left[n_{f}\left(t, \tilde{a}, h\left(\tilde{a}, z, z^{\prime}\right), z, z^{\prime}\right) \epsilon_{z}(t+T)+n_{s}\left(t, \tilde{a}, h\left(\tilde{a}, z, z^{\prime}\right), z, z^{\prime}\right) \epsilon_{z^{\prime}}(t)\right] ;$

Good market:

$$
\begin{gathered}
K^{\alpha} N^{1-\alpha}-\delta K= \\
\sum_{A \times Z \times Z} X\left(\widetilde{a}, z, z^{\prime}\right) \sum_{t=1}^{T}\left[c_{f}\left(t, \tilde{a}, h\left(\widetilde{a}, z, z^{\prime}\right), z, z^{\prime}\right)+c_{s}\left(t, \tilde{a}, h\left(\widetilde{a}, z, z^{\prime}\right), z, z^{\prime}\right)\right] .
\end{gathered}
$$

5. The distribution of states of households satisfies

$$
X\left(A \times Z_{1} \times Z_{2}\right)=\sum_{D} \sum_{z^{\prime \prime} \in Z_{2}} X\left(\tilde{a}, z, z^{\prime}\right) \pi_{z^{\prime} z^{\prime \prime}}
$$

where $D \equiv\left\{\left(\tilde{a}, z, z^{\prime}\right) \in G \times Z \times Z: h\left(\tilde{a}, z, z^{\prime}\right) \in A\right.$ and $\left.z^{\prime} \in Z_{1}\right\}$.

6. Social security is self-financing, ${ }^{28}$

$$
\begin{gathered}
\tau \omega \sum_{A \times Z \times Z} X\left(\tilde{a}, z, z^{\prime}\right) \sum_{t=1}^{T}\left[n_{f}\left(t, \tilde{a}, h\left(\tilde{a}, z, z^{\prime}\right), z, z^{\prime}\right) \epsilon_{z}(t+T)+n_{s}\left(t, \tilde{a}, h\left(\tilde{a}, z, z^{\prime}\right), z, z^{\prime}\right) \epsilon_{z^{\prime}}(t)\right]= \\
(2 T-R+1) \cdot \sum_{A \times Z \times Z} X\left(\tilde{a}, z, z^{\prime}\right) \sum_{z^{\prime \prime} \in Z} b\left(m\left(\tilde{a}, z, z^{\prime}, z^{\prime \prime}\right)\right) \cdot \pi_{z^{\prime} z^{\prime \prime}}
\end{gathered}
$$

\footnotetext{
${ }^{28}$ Note that $\omega \sum^{T}\left[\left(n_{s}\left(t, \tilde{a}, h\left(\tilde{a}, z, z^{\prime}\right), z, z^{\prime}\right) \epsilon_{z^{\prime}}(t)+n_{f}\left(t, h\left(\tilde{a}, z, z^{\prime}\right), h\left(h\left(\tilde{a}, z, z^{\prime}\right), z^{\prime}, z^{\prime \prime}\right), z^{\prime}, z^{\prime \prime}\right) \epsilon_{z^{\prime}}(t+T)\right]\right.$

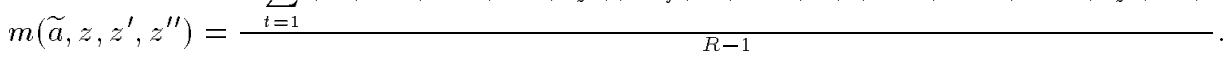




\subsection{Algorithm to Compute Equilibrium}

1. Guess the aggregate capital stock $K_{0}$, the aggregate labor $N_{0}$, and the social security tax $\tau_{0}$. Obtain the relative prices of capital and labor $(r, \omega)$.

2. For each point of the grid $G \times G \times Z \times Z$, solve the finite horizon problem of a household, (2.4), to obtain the function $F\left(\tilde{a}, \tilde{a}^{\prime}, z, z^{\prime}\right)$.

3. Use the matrix $F(G \times G \times Z \times Z)$ to solve in (2.5) for the optimal policy function of final assets of a household, $h(G \times Z \times Z)$.

4. Guess the invariant distribution function of states of households, $X_{0}(G \times Z \times Z)$, and use the function $h$ to iterate in (5.1) until convergence to $X^{*}$.

5. Compute aggregate consumption $C$, aggregate supply of labor $N$ using $X^{*}$.

6. Use Newton's method with numerical derivatives to solve the system of equations:

$$
\begin{gathered}
f_{1}\left(K_{0}, N_{0}, \tau_{0}\right)=F\left(K_{0}, N_{0}\right)-\delta K_{0}-C \\
f_{2}\left(K_{0}, N_{0}, \tau_{0}\right)=\tau_{0} \omega N-(2 T-R+1) \sum_{G \times Z \times Z} X^{*}\left(\widetilde{a}, z, z^{\prime}\right) \sum_{z^{\prime \prime} \in Z} b\left(m\left(\widetilde{a}, z, z^{\prime}, z^{\prime \prime}\right)\right) \cdot \pi_{z^{\prime}, z^{\prime \prime}} \\
f_{3}\left(K_{0}, N_{0}, \tau_{0}\right)=N_{0}-N
\end{gathered}
$$

until convergence. 


\section{References}

[1] Abel, A. B. , (1985), "Precautionary Saving and Accidental Bequests", American Economic Review, Vol. 75: 777-791.

[2] Altig, D. and S. J. Davis (1993), "Borrowing Constraints and Two-sided Altruism with an Application to Social Security", Journal of Economic Dynamics and Control, Vol. 17: 467-494.

[3] Auerbach, A. J. and L. J. Kotlikoff (1987), Dynamic Fiscal Policy, New York, N. Y.: Cambridge University Press.

[4] Barro, R. J. (1974), “Are Government Bonds Net Wealth?”, Journal of Political Economy, Vol. 82: 1095-1117.

[5] Barsky, R. B. , N. G. Mankiw, and S. P. Zeldes (1986), "Ricardian Consumers with Keynesian Propensities", American Economic Review, Vol. 76: 676-691.

[6] Bewley, T. F. "Interest Bearing Money and the Equilibrium Stock of Capital", mimeo, undated.

[7] Bureau of the Census (1991), "Money Income of Households, Families, and Persons in the United States".

[8] Cubeddu, L. M. (1996), "The Intra-Generational Redistributive Effects of Social Security", Universitat Pompeu Fabra, Working Paper 168.

[9] Fuster, L. (1994), "Altruism, Uncertain Lifetime, and the Distribution of Wealth", Ph. D. Dissertation, Universitat Autònoma de Barcelona.

[10] Hansen, G. D. (1993), "The Cyclical and Secular Behavior of the Labor Input: Comparing Efficiency Units and Hours Worked", Journal of Applied Econometrics, Vol. 8: 71-80. 
[11] Hubbard, R.G. and K.L. Judd (1987), "Social Security and Individual Welfare: Precautionary Saving, Liquidity Constraints, and Payroll Tax", American Economic Review, Vol. 77(4): 630-646.

[12] Huggett, M. (1997), "The One-Sector Growth Model with Idiosyncratic Shocks: Steady State and Dynamics", Journal of Monetary Economics Vol. 39 (2).

[13] Hurd, M. D. (1987), "Savings of the Elderly and Desired Bequests", The American Economic Review, Vol. 77(3): 298-312.

[14] Hurd, M. D. (1989), "Mortality Risk and Bequests", Econometrica, Vol. 57 (4): $779-813$.

[15] Hurd, M. D. and J. Shoven (1985), "Inflation Vulnerability, Income, and Wealth of the Elderly, 1969-1979", Horizontal Equity, Uncertainty, and Economic WellBeing, Martin David and Tim Smeeding, eds., NBER, Chicago: University of Chicago Press.

[16] Imrohoroglu, A., S. Imrohoroglu, and D. Joines (1995), “A Life Cycle Analysis of Social Security", Economic Theory, Vol. 6 (June): 83-114.

[17] Juster and Laitner, J. (1996), “New Evidence on Altruism: A Study of TIAACREF Retirees", The American Economic Review, Vol. 86(4): 893-908.

[18] Kydland, F. E. and E. C. Prescott (1996), "The Computational Experiment: An Econometric Tool", Journal of Economic Perspectives, Vol. 10(1): 69-85.

[19] Laitner, J. (1988), "Bequests, Gifts, and Social Security", Review of Economic Studies, Vol. 55: 275-299.

[20] Laitner, J. (1991), “Modeling Marital Connections among Family Lines”, Journal of Political Economy, Vol. 99(6):

[21] Laitner, J. (1992), "Random Earnings Differences, Lifetime Liquidity Constraints, and Altruistic Intergenerational Transfers", Journal of Economic Theory, Vol. 58: 135-170. 
[22] Prescott, E. C. (1986), “A Theory Ahead of Business Cycle Measurement", Federal Reserve Bank of Minneapolis Quarterly Review, Fall: 9-22.

[23] Solon, G. ,(1992), "Intergenerational Income Mobility in the U. S.", American Economic Review, Vol. 82(3): 393-408.

[24] Zimmerman, D. (1992), "Regression Toward Mediocrity in Economic Stature", American Economic Review, Vol. 82(3): 409-429. 